\title{
ATENÇÃO À SAÚDE NAS UNIDADES DE CONSERVAÇÃO AMBIENTÁL NO AMAZONAS: CONFLITOS DE COMPETÊNCIA OU QUESTÃO DE RESPONSABILIDADE?
}

\section{Health care in Environmental Conservation Units in Amazonas: conflicts of competence or question of responsibility?}

\author{
Marcilio Sandro de Medeiros \\ Fundação Oswaldo Cruz. Instituto Leônidas e Maria Deane \\ muribeka@hotmail.com \\ Daniel Souza Sacramento \\ Secretaria Municipal de Saúde de Manaus \\ dsacramento.am@gmail.com \\ Inez Siqueira Santiago Neta \\ Universidad de Buenos Aires. Facultad de Medicina \\ inez santiago@hotmail.com \\ Rita Suely Bacuri de Queiroz \\ Fundação Oswaldo Cruz. Instituto Leônidas e Maria Deane \\ ritabacuri.olimpiada.fiocruz@gmail.com
}

Stefania Barca Universidade de Coimbra. Centro de Estudos Sociais sbarca68@gmail.com

Lia Giraldo da Silva Augusto; Fundação Oswaldo Cruz. Instituto Aggeu Magalhães. lgiraldo@uol.com.br

Solange Laurentino dos Santos Centro de Ciências Médicas da Universidade Federal de Pernambuco solaurentino@hotmail.com

André Monteiro Costa Fundação Oswaldo Cruz. Instituto Aggeu Magalhães.

Recebido em 01/11/2020 andremc@cpqam.fiocruz.br

Aceito em 14/12/2020

RESUMO: Este artigo analisa as representações discursivas no pensamento coletivo dos socioambientalistas sobre as competências e responsabilidades da política de áreas protegidas com a atenção à saúde das populações ribeirinhas. Estudo exploratório descritivo de abordagem qualitativa a partir do pensamento coletivo dos socioambientalistas atuantes na política de áreas protegidas da Reserva de Desenvolvimento Sustentável Mamirauá a partir de sete entrevistas coletadas por meio de roteiro semiestruturado e analisadas pela técnica do Discurso do Sujeito Coletivo. Os entrevistados expressam conhecimento sobre as competências constitucionais do município com a saúde, mas têm dificuldade de diálogo com as prefeituras sobre o assunto; as responsabilidades da gerência das unidades de conservação (UC) e organizações públicas não estatais que atuam no apoio à cogestão são atribuídas a responsabilidade de capitaneador das políticas públicas e de formulador de informações cientificas para melhoria da saúde local. A ausência de diálogo soma-se à falta de uma 
agenda pública no âmbito da política ambiental. Há experiências de acesso à saúde na zona rural adaptadas ao contexto socioambiental da reserva, contudo, essas sofrem descontinuidade. As representações discursivas do pensamento coletivo dos socioambientalistas expressam conhecimento sobre as competências municipais com a saúde e preocupações em relação ao atendimento destas necessidades. $\mathrm{O}$ atendimento às necessidades sociais está organizado de forma conflituosa, e isso acontece devido à falta de articulação entre as várias instituições que atuam nesse território. A descentralização das competências e das responsabilidades sobre os recursos naturais por meio da cogestão das UCs impôs novos papéis e autoridades sobre os territórios.

Palavras-chave: Pesquisa qualitativa; Discurso do Sujeito Coletivo; Áreas Protegidas; Necessidades e Demandas de Serviços de Saúde; Populações Vulneráveis.

ABSTRACT: This article analyzes the discursive representations in the collective thinking of socioenvironmentalists about the competencies and responsibilities of the policy of protected areas with the attention to the health of the riverside populations. The method is an exploratory descriptive of qualitative approach based on the collective thinking of socioenvironmentalists working in the protected areas policy of Mamirauá Sustainable Development Reserve from seven interviews collected through a semistructured script which were analyzed by the Collective Subject Discourse technique. Respondents express knowledge about the constitutional competences of the municipality with health, but they have difficulty in dialogue with the city halls on the subject; the responsibilities of the management of conservation units (UC) and public non-state organizations that work in support of co-management are attributed the responsibility as to captain the public policies and the formulator of scientific information for the improvement of local health. The absence of dialogue adds to the lack of a public agenda within the scope of environmental policy. There are experiences of access to health in the rural area adapted to the socio-environmental context of the reserve, however, these suffer discontinuity. The discursive representations of the collective thinking of socioenvironmentalists express knowledge about municipal competences with health and concerns regarding meeting these needs. The meeting of social needs is organized in a conflictual manner, and this is due to the lack of coordination between the various institutions that operate in this territory. The decentralization of competences and responsibilities over natural resources through the co-management of UCs imposed new roles and authorities on the territories.

Keywords: Investigación cualitativa; Discourse of the collective subject; Protected Areas; Health Services Needs and Demand; Vulnerable Populations.

\section{INTRODUÇÃO}

As unidades de conservação (UCs) são áreas destinadas à proteção e à conservação da biótica (fauna e flora), sendo a mais antiga e efetiva iniciativa para a conservação da natureza no mundo (GODOY; LEUZINGE, 2015).

No Brasil, existem registradas no Sistema Nacional de Unidades de Conservação (Snuc) 1.940 UCs, correspondendo a cerca de $17 \%$ do território nacional. Em relação à sua distribuição por grandes regiões geográficas e biomas do país, a Região Norte e o bioma amazônico são os mais contemplados em termos de número de áreas protegidas, possuindo 307 unidades abrangendo 23,5\% da Amazônia Legal (15,8\% do total) (AMAZONAS, 2015; BRASIL, 2011; VERÍSSIMO et al., 2011).

Na Amazônia Legal, a população que vive dentro e no entorno das UCs federais é de 1.345 .635 pessoas ( $11,3 \%$ da população total do estado), estimada a partir do método geoestatístico da contagem populacional de 2007, indicando-se a dimensão social nesse contexto (D'ANTONA et al., 2013).

O Amazonas é o segundo Estado da Amazônia Legal em número de Unidades (71 UCs, sendo 30 federais e 41 estaduais) e em extensão territorial de UCs (27\% da área 
total do Estado). Nele, ainda se registra uma inovação em termos de tipologia de Unidade de Conservação, categorizada como sendo de Uso Sustentável (UUS), que é a Região de Desenvolvimento Sustentável (RDS). Essa categoria e tipologia admitem a presença de populações humanas em seu interior, com o objetivo de compatibilizar a conservação da natureza com o uso sustentável de uma parcela de seus recursos naturais, diferentemente da categoria denominada de Proteção Integral (UPIs), a qual não permite a interferência humana de forma direta (AMAZONAS, 2015; VERÍSSIMO et al., 2011; MOURA, 2007).

A consolidação das funções ambientais e sociais das UCs tem sido objeto de pesquisas, dado a importância e dificuldade da gestão dessas áreas para que se tornem indutoras de ações voltadas ao desenvolvimento sustentável local e à equidade social, o que talvez não venha ocorrendo por envolver múltiplos atores e interesses (comunidades biológicas, comunidades humanas locais, organizações governamentais e não governamentais, usuários e iniciativa privada) passíveis de conflitos (MARTINS, 2012; GUERRA; COELHO, 2009, MEDEIROS; IRVING, 2007).

A noção de conflito tem sido apresentada no campo da sociologia ambiental e da ecologia política como alternativa para evidenciar a heterogeneidade de interesses e de relações que regem os processos societários nas UCs, o que também traduz uma mudança de foco de visão crítica e politizada, menos romântica, dessa realidade (MARTINS, 2012; FERREIRA, 2005; GUIVANT, 2005).

Notadamente, é possível identificar os conflitos nas representações discursivas do pensamento coletivo sobre as mudanças nas funções ambientais e sociais das UCs, sendo possível falar de atribuição de múltiplos sentidos sobre esses espaços, ou múltiplas territorialidades, o que, do ponto de vista paradigmático, foi conceituado pelos cientistas modernos como preservacionismo, conservacionismo, biodiversalismo e socioambientalismo na era moderna (FRANCO, 2013; SOUZA, 2013; SANTILLI, 2005; VALLEJO, 2005; HAESBAERT, 2005).

As territorializações advindas da política ambiental e da política de saúde foram originadas de competências e responsabilidades estabelecidas pela Magna Carta do país, formuladas em períodos distintos e, muitas vezes, derivaram de agendas públicas diferentes. Argumentamos que, ao considerar nas representações discursivas dos socioambientalistas os pontos conflituosos no que tange ao atendimento às necessidades relacionadas à saúde, poderão ser reveladas as relações de poder e as dinâmicas dos territórios.

Nessa perspectiva, este estudo analisa o que pensam os socioambientalistas sobre as competências e responsabilidades da política de áreas protegidas no atendimento às necessidades de saúde das populações ribeirinhas.

\section{MATERIAIS E MÉTODOS}

O desenho do estudo é exploratório descritivo, de abordagem qualitativa a partir do pensamento coletivo dos socioambientalistas atuantes na política de áreas protegidas no Estado do Amazonas. 
A área de estudo é a Reserva de Desenvolvimento Sustentável Mamirauá (RDSM) que é uma das 15 UCs do Estado do Amazonas organizadas sob essa tipologia. A RDSM foi criada pela organização não estatal e regulamentada pelo Decreto Estadual nº 12.836/96. Desde o ano 2000, ela é considerada a maior área de várzea do mundo sob proteção ambiental, sendo o resultado dessa experiência aguardado com grande expectativa em relação a seu discurso de sustentabilidade. (AMAZONAS, 2015).

A reserva tem uma extensão de 1.124 .000 hectares que compreende as Regiões de Saúde do Triângulo e do Alto Solimões do Estado do Amazonas, especificamente, distribuída sobre os municípios de Alvarães, Fonte Boa, Japurá, Juruá, Jutaí, Maraã, Tonantins e Uarini, onde vivem 10.867 pessoas distribuídas em 200 comunidades e em 1.873 domicílios, segundo o último censo demográfico do IDSM de 2011(MOURA et al., 2016).

A seleção da RDSM deveu-se ao fato desta UC ser a única entre as UCs no Amazonas que conta com um instituto de pesquisa não estatal vinculado ao Ministério de Ciência, Tecnologia e Inovação (MCTI), o qual guarda uma relação histórica com a reserva e seus moradores.

O grupo de participantes da pesquisa foi composto por sete entrevistados selecionados pelo critério de maior representatividade social dentre os representantes identificados no mapeamento das organizações públicas estatais e organizações públicas não estatais. A partir dos primeiros entrevistados, foram solicitados novos nomes no intuito de responder a novas indagações. No tocante à política e áreas protegidas, o critério de seleção aconteceu por meio da representatividade social do participante perante seus pares e a sociedade.

Os dados foram coletados por meio de entrevista individual, a partir de um roteiro semiestruturado, que continha perguntas direcionadoras sobre os conflitos de competências e a crise de responsabilidade da-com a atenção à saúde na área da reserva; a existência de agenda pública ambiental das UCs; a estrutura política necessária para atendimento às necessidades de saúde; as implicações jurídicas e políticas das sobreposições territoriais e; a intersetorialidade entre a política ambiental e a política municipal de saúde.

As entrevistas foram gravadas em aparelho de MP3 e transcritas na íntegra, respeitando o anonimato dos participantes, identificados como $\mathrm{P} 1, \mathrm{P} 2, \mathrm{P} 3$, etc. Antecederam às entrevistas abertas individuais a apresentação dos objetivos da pesquisa e a leitura e assinatura do Termo de Consentimento Livre e Esclarecido (TCLE).

Os dados foram analisados de acordo com a técnica do Discurso do Sujeito Coletivo (DSC) desenvolvido por Lefèvre e Lefèvre (2005), O pensamento coletivo como unidade de análise difere das pesquisas de abordagem quantitativa, às quais exploram algo que as pessoas efetivamente têm e já está dado antes da pesquisa, como peso, altura, renda, etc. Em se tratando de um pensamento, de uma ideia ou de uma opinião, o "algo", representando aqui é sempre o que as pessoas expressam sobre determinado tema que se apresenta em forma de um discurso. 
A análise do conteúdo discursivo é compreendida a partir das expressões-chave $(\mathrm{ECH})$, das ideias centrais (IC) e da ancoragem (AC). As ECH são extraídas de trechos mais significativos das respostas dos entrevistados que dividem o conteúdo discursivo. As IC são trechos iluminados das respostas, os quais se constituem de palavras ou expressões linguísticas que revelam o sentido presente nos depoimentos de modo objetivo e sintético. A AC, manifestam linguisticamente teorias, ideologias ou crenças na condição de afirmações genéricas e definidoras de uma determinada situação, e nem sempre são verificadas nos discursos. Cada DSC foi associado à ideia central (síntese) correspondente para que fosse possível analisar as entrevistas colhidas. Dessa forma, tornou-se viável reunir os depoimentos (DSC) de sentido semelhante, porém identificados em sua singularidade e, analisá-los à luz do conhecimento disponível. (NICOLAU et al., 2015; LEFÉVRE; LEFÉVRE, 2005).

Os DSC foram agrupados nas seguintes categorias:

a) Conflitos de competências e a crise de responsabilidade com a saúde:

Para fins de definições, as competências constitucionais podem ser entendidas como a capacidade jurídica de agir de um ente federado ou órgão público em uma determinada matéria (MACHADO, 2016); enquanto que responsabilidades constitucionais ensejam atribuições e obrigações de todos os entes federados ou órgão público de assegurar, a favor do cidadão e da coletividade, o acesso efetivo do direito (PAIM, 2002).

b) Agenda pública ambiental das UCs para a garantia do cuidado à saúde:

A agenda pública pode ser compreendida como o processo de inclusão ou inscrição de uma temática no debate político local. Em resumo, é o primeiro passo na construção da ponte entre a sociedade e o governo, no que diz respeito à busca de respostas para as necessidades ou soluções para os problemas da sociedade por meio de medidas cabíveis do Poder Executivo (assim como também dos Poderes Legislativo e Judiciário) (GOTTEMS et al., 2013; KINGDON, 2003).

c) Pensando a política da atenção à saúde dos ribeirinhos:

A noção de política enseja é a que orienta a decisão e a ação, sentido mais empregado para definir e compreender as políticas públicas, sendo esse também a noção explorada pelas pesquisas científicas. Em geral, sua análise permite complementar e ir além do estudo do Estado enquanto ente, funções e aparatos legais e burocráticos, para verificar como atua, decide, interfere e impacta os problemas por meio de políticas públicas (SECCHI, 2010; MULLER; SUREL, 2004).

O termo "atenção à saúde" é uma noção que compreende a forma de organização e as estratégias de ação de uma sociedade em resposta às necessidades de saúde da população que se expresse de forma articulada com as situações demográficas e epidemiológicas singulares vigentes (MENDES, 2011; MATTA; MOROSINI, 2009)

d) Parcerias interinstitucionais e intersetoriais para o atendimento às necessidades de saúde na Reserva Mamirauá:

Essa categoria buscou identificar a existência de intersetorialidade entre a política ambiental e a política municipal de saúde no contexto da RDSM a partir da 
identificação de projetos elaborados em parceria entre a gestão da UC e a gestão municipal.

A Constituição Federal, de 1988, trouxe à gestão das políticas pública, grandes desafios em relação ao reconhecimento de direitos e de garantias fundamentais e a efetivação dos direitos sociais prescritos como universais, incluindo a democratização do poder. A ação integrada, ou seja, a intersetorialidade objetiva superar os modelos fragmentados de gestão, compartilhar recursos, metas e desenvolvendo estratégias conjuntas a partir das experiências já vivenciadas, trazendo a cena uma maior participação de todos os atores envolvidos nas políticas sociais, inclusive os destinatários de tais políticas (CARMO; GUIZARDI, 2017)

O projeto foi aprovado pelo Parecer nำ1.667.857 do Comitê de Ética em Pesquisa do Centro de Pesquisas Aggeu Magalhães (CPqAM) da Fundação Oswaldo Cruz.

\section{RESULTADOS E DISCUSSÕES}

Dentre os sete entrevistados participantes, cinco eram do sexo masculino e dois do sexo feminino. A maioria dos entrevistados tem curso superior (seis) com pósgraduação em biologia (três), engenharia de pesca (dois) e antropologia (um) e apenas um entrevistado tinha escolaridade com nível fundamental, apenas quatro residem na reserva.

\section{Conflitos de competências e responsabilidade com a saúde}

Os DSC das três primeiras ideias centrais demonstram o conhecimento dos entrevistados sobre alguns aspectos constitucionais que orientam a organização dos serviços públicos de saúde e educação. Por outro lado, apontam formas diferenciadas de dialogar com os gestores desses serviços sociais no âmbito da gestão da UC. Apesar dos entrevistados destacarem a limitação financeira da gestão e os desafios impostos pela extensão territorial da Reserva, eles afirmam conseguir dialogar mais com o setor da educação em nível estadual, sendo esse o mesmo nível administrativo de governo em que se encontra a gestão da UC (Quadro 1).

$\mathrm{Na}$ quarta ideia central se reconhece a responsabilidade da gestão da UC com a saúde e atribui a função de "capitaneador das políticas públicas" à gestão da UC. Outra responsabilidade atribuída, diz respeito à produção de conhecimento científico. Segundo eles, caberia a essas organizações sociais "mostrarem através da pesquisa quão frágil é a questão da saúde em todos aspectos, uma pesquisa dessa natureza pode nos subsidiar para muitas coisas" (Quadro 1). 
Quadro 1 Competências e responsabilidade da UC com a saúde. RDSM, 2016.

\begin{tabular}{|c|c|}
\hline IC (síntese) & DSC \\
\hline $\begin{array}{c}\text { (1) A gestão da UC } \\
\text { não é responsável } \\
\text { pela saúde }\end{array}$ & $\begin{array}{c}\text { Eu entendo que cada setor do governo tem mandato para atuar em relação } \\
\text { a uma temática. A parte da saúde não depende muito da reserva. Você } \\
\text { sabe que educação e saúde é via município. }\end{array}$ \\
\hline $\begin{array}{c}\text { (2) A gestão da UC } \\
\text { não tem estrutura e } \\
\text { nem recurso } \\
\text { financeiro }\end{array}$ & $\begin{array}{c}\text { Eu acho difícil uma entidade assim. A reserva Mamirauá além de ser } \\
\text { grande, é uma língua de terra que se estende por vários municípios. A } \\
\text { gente da gestão da UC não tem recurso para isso, não tem recursos nem } \\
\text { para resolver as questões ligadas à organização das UCs e à própria } \\
\text { proteção da vigilância, monitoramento da biodiversidade. }\end{array}$ \\
$\begin{array}{c}\text { (3) A gestão da UC } \\
\text { entra como } \\
\text { papitaneador das }\end{array}$ & $\begin{array}{c}\text { A gestão da UC entra como capitaneador das políticas públicas. As } \\
\text { necessidades das comunidades chegam através do conselho, mas não são } \\
\text { executadas diretamente pelo gestor da UC. }\end{array}$ \\
$\begin{array}{c}\text { Eu acho que a missão do Mamirauá IDSM ou das entidades que prestam } \\
\text { apoio da gestão da UC é mostrar através da pesquisa quão frágil é a } \\
\text { questão da saúde em todos aspectos, uma pesquisa dessa natureza pode } \\
\text { nos subsidiar para muitas coisas. }\end{array}$ \\
$\begin{array}{c}\text { (4) A } \\
\text { responsabilidade da } \\
\text { gestão da UC com a } \\
\text { educação é diferente }\end{array}$ & $\begin{array}{c}\text { Com a educação é diferente, hoje, por exemplo, tive uma agenda com o } \\
\text { pessoal da educação. Mas isso depende muito do gestor e do nível de } \\
\text { governo, em algumas unidades de conservação tem escola estadual, } \\
\text { núcleo de sustentabilidade da Fundação Amazônia Sustentável (FAS). }\end{array}$ \\
\hline
\end{tabular}

Fonte: os autores

A garantia de direitos à saúde e ao meio ambiente saudável e equilibrado, no âmbito de nossa sociedade, é de responsabilidade de diferentes instituições que atuam de acordo com suas competências, sendo essa a interpretação constitucional. As competências típicas do modelo constitucional federalista brasileiro ainda preveem a descentralização do Poder em vários centros autônomos coordenados por um poder central, cuja peculiaridade do modelo brasileiro é a inclusão dos Municípios como membros (MACHADO, 2016).

Em matéria de saúde, prevaleceu a ideia de descentralização na Constituição Federal de 1988, com menção à municipalização dos serviços públicos que orientou o Sistema Único de Saúde do país. Além de atribuir competências comuns à União, aos Estados e ao Distrito Federal, a Carta Federal atribui12 competências aos Municípios na gestão do sistema público de saúde, no que tange à formulação de políticas de âmbito local, ao planejamento, à organização, à execução, à avaliação e ao controle das ações e serviços de saúde (PAIM, 2002).

A agenda política que culminou com o projeto de Lei no 2.892/1992, que posteriormente criou o SNUC, teve por base os Planos do Sistema de Unidades de Conservação do Brasil do Instituto Brasileiro de Desenvolvimento Florestal (IBDF) de 1979 e 1982, cujo trabalho foi retomado pelo Instituto Brasileiro do Meio Ambiente e dos Recursos Naturais Renováveis (IBAMA) em 1989, sob o nome de Sistema Nacional de Unidade de Conservação (SISNAMA), que tramitou durante quase uma década para ser aprovado no Congresso Nacional (WALLAUER, 1998). 
ATENÇÃO À SAÚDE NAS UNIDADES DE CONSERVAÇÃO AMBIENTAL NO AMAZONAS: CONFLITOS DE COMPETÊNCIA OU QUESTÃO DE RESPONSABILIDADE?

Em uma análise crítica, podemos afirmar que as orientações filosóficas e políticas dos atores envolvidos no estabelecimento de um Sistema Nacional de Unidades de Conservação eram quase todas conservacionistas, oriundas do sul e sudeste do país. Eram elas representadas nas figuras de Paulo Nogueira Neto, que criou a categoria de reserva de proteção integral, e de Maria Tereza Jorge Pádua, primeira dirigente do Instituto Brasileiro de Desenvolvimento Florestal (IBDF) e da Fundação Pró-natureza (FUNATURA), que teve forte presença na Frente Verde da Assembleia Nacional Constituinte, essa que congregava mais de 80 Deputados e Senadores de todos partidos políticos, cuja liderança era do Deputado Fábio Feldmann, de São Paulo (GODOY; LEUZINGE, 2015).

Santilli (2005) constata que a ênfase das legislações produzidas nesse período era sobre o controle por meio da repressão a práticas lesivas ao meio ambiente, essas realizadas, principalmente, pelo Ibama, criado em 1989 e ligado ao SISNAMA. As leis tinham como intuito salvaguardar as espécies dos ecossistemas, com forte orientação conservacionista, sem uma dimensão social claramente incorporada, o que começou a mudar a partir dos desdobramentos da aliança entre os povos das florestas, movimentos sociais e ambientalistas no período de redemocratização do país, denominado socioambientalismo, explica a autora.

Desde 2004, tramita no Congresso Nacional o Projeto Lei n 4.573/2004 que dispõe a respeito da regulamentação sobre os critérios de seleção e das atribuições e responsabilidades das Organização da sociedade civil de interesse público (Oscips) na gestão das UCs. Para o projeto de lei, a gestão compartilhada é uma forma de aproveitar a capacidade técnica de entidades não governamentais ligadas ao meio ambiente.

\section{Agenda política e ambiental das UCs para a garantia do cuidado à saúde dos povos e comunidades do Mamirauá}

$\mathrm{Na}$ ideia central (1) os entrevistados culpam a legislação ambiental que não permite o desenvolvimento de iniciativas para solucionar as queixas de saúde e problemas de acesso aos serviços de saúde nas comunidades ribeirinhas. Já na ideia central (2), os entrevistados reconhecem a carência dos serviços de saúde na área da Reserva Mamirauá, contudo, admitem que o problema não está claro na agenda de trabalho das instituições ambientais em que trabalham, o que pode significar falta de conhecimento sobre a organização e funcionamento do setor saúde (Quadro 2).

Bentes (2006) explica que o Snuc sob a tipologia de Reserva de Desenvolvimento Sustentável (RDS) alude compatibilizar a preservação com a sobrevivência dos seus moradores, dando a essa política um caráter de sustentabilidade. Na interpretação da jurista, cuja ideia também compartilhamos, cabe ao Estado (nas instâncias Federal, Estadual e Municipal) e à instituição responsável pela administração da Reserva ofertar os meios necessários para um indivíduo viver em sociedade e, assim, promover o desenvolvimento sustentável, finalidade maior da RDS.

Contudo, Calegare e colaboradores (2013) constatou em duas UCs federais, também no estado do Amazonas, o uso da etnicidade como meio para garantir o acesso aos 
ATENÇÃO À SAÚDE NAS UNIDADES DE CONSERVAÇÃO AMBIENTAL NO AMAZONAS: CONFLITOS DE COMPETÊNCIA OU QUESTÃO DE RESPONSABILIDADE?

serviços de saúde e de educação. nesse contexto, situação constatada também pela pesquisa na comunidade de São Francisco do Aiucá, na Área de Uarini da Reserva Mamirauá.

\section{Quadro 2 - Agenda política das UCs para a garantia do cuidado à saúde dos povos e} comunidades do Mamirauá. RDSM, 2016.

\begin{tabular}{|c|c|}
\hline IC (síntese) & DSC \\
\hline $\begin{array}{c}\text { (1) A saúde não é } \\
\text { uma prerrogativa da } \\
\text { secretaria do meio } \\
\text { ambiente. }\end{array}$ & $\begin{array}{c}\text { Não tem nenhum planejamento, não tem nenhuma agenda, não tem nada } \\
\text { nesse sentido até o momento. }\end{array}$ \\
$\begin{array}{c}\text { Anualmente é realizado assembleia geral da RDSM onde levanto as } \\
\text { prioridades e discuto as questões sociais, mas o plano de atividade não } \\
\text { está vinculado a essa questão das políticas públicas de saúde. Porque a } \\
\text { secretaria estadual do meio ambiente não entende isso como uma } \\
\text { obrigação do gestor e a gestão é muito travada, não tem verbas e as leis } \\
\text { não permitem. }\end{array}$ \\
\hline $\begin{array}{c}\text { (2) A agenda de } \\
\text { saúde é estratégica }\end{array}$ & $\begin{array}{c}\text { No ano passado foi tocado na FAS muito nesse assunto da saúde para se } \\
\text { achar uma solução. Como estou 24 horas nas comunidades, sei da } \\
\text { necessidade e carência incrivel com a saúde. Deveria aparecer muito mais. } \\
\text { A nossa tendência é buscar soluções para resolver. Mas também não está } \\
\text { clara essa questão na agenda. A saúde é uma agenda estratégica. }\end{array}$ \\
\hline \multicolumn{1}{|c|}{ Fonte: os autores }
\end{tabular}

Fonte: os autores

Recentemente, o Tribunal de Contas do Estado do Amazonas (2015), em avaliação do Sistema de Unidades de Conservação do Amazonas (SEUC-AM), enumerou nove problemas que comprometem o futuro almejado da política de proteção ambiental, dentre os quais, destacamos: problemas de recategorização, redefinição e adequação de UCs; baixa efetividade para a regularização fundiária das UCs; insuficiência de recursos humanos e financeiros para a gestão e a operação das UCs; enfraquecimento político e até extinção de órgãos estaduais no âmbito da reforma do atual Governo do Estado; e baixo acesso das UCs estaduais às políticas públicas. $\mathrm{O}$ documento ainda ressalta que a adoção de agendas de proteção ambiental não foi acompanhada por outras políticas de cunho social, o que tem contribuído negativamente para a baixa qualidade de vida das populações residentes no entorno de UCs, deterioração dos ecossistemas e proliferação de endemias (AMAZONAS, 2015).

\section{Pensando a estruturação da política para o atendimento às necessidades de saúde das populações da Reserva Mamirauá RDSM.}

No discurso da ideia central (1) a noção de saúde é ampliada e o monitoramento das condições socioambientais, descrito no plano de gestão da UC, poderia reduzir a vulnerabilidade das populações locais. Essa percepção tenta superar a ideia de saúde como ausência de doença, o que corrobora com a ideia central (2), quando os entrevistados atribuem à gestão da UC a responsabilidade de levantar e conhecer as queixas de saúde mais frequentes, como também de mobilizar, articular e cooperar 
de forma técnica e financeira as ações de proteção à saúde dos ribeirinhos. Até porque, vale salientar, há conhecimento dos entrevistados sobre estratégias e tecnologias de saúde (Ambulancha; barco da saúde; unidade de saúde fluvial) mais adequadas às condições geográficas, cujas iniciativas, infelizmente, sofrem descontinuidade (Quadro 3).

\section{Quadro 3 - Pensando a estruturação de ações para o atendimento às necessidades de saúde dos povos e comunidades do Mamirauá. RDSM, 2016.}

\begin{tabular}{|c|c|}
\hline IC (síntese) & DSC \\
\hline $\begin{array}{l}\text { Vai depender } \\
\text { daquilo que nós } \\
\text { estamos falando } \\
\text { por saúde }\end{array}$ & $\begin{array}{c}\text { Eu acho que depende também daquilo que estou definindo por saúde, no } \\
\text { sentido bastante amplo. Se o gestor da UC se dá ao trabalho de levantar as } \\
\text { principais queixas de saúde e de compreender as doenças mais frequentes } \\
\text { que estão afetando a população, ele vai acabar chegando muito rapidinho } \\
\text { numa questão ambiental, é óbvio que ele não vai tratar das questões da } \\
\text { saúde como a sua agenda de fazer, mas ele pode, sim, articular e facilitar } \\
\text { processos importantes. }\end{array}$ \\
\hline $\begin{array}{l}\text { A gestão da UC } \\
\text { poderia mobilizar, } \\
\text { articular e cooperar } \\
\text { de forma técnica e } \\
\text { financeira com as } \\
\text { ações de saúde }\end{array}$ & $\begin{array}{l}\text { O gestor da UC tem que buscar que a população residente dentro de sua } \\
\text { área protegida tenha acesso à saúde. Ele tem que realizar levantamento, } \\
\text { consultar as comunidades, aprofundar o entendimento sobre as principais } \\
\text { queixas de saúde atribuídas às questões ambientais. É preciso ser feita uma } \\
\text { agenda, um grupo de trabalho que tratasse dessa questão específica da } \\
\text { saúde dentro da A Associação de Moradores e Usuários da Reserva } \\
\text { Mamirauá Antônio Martins (Amurmam) e dentro do conselho da reserva. A } \\
\text { Amurmam tem força, ela representa todas as associações, só não tem mais } \\
\text { força que o conselho geral da reserva. } \\
\text { Deve ter um acordo de cooperação técnica com o município, a gestão da } \\
\text { UC deve arcar com o ônus da responsabilidade da saúde. Eu lembro que } \\
\text { em } 2003 \text { tinha uma lancha itinerante, com médico e enfermeiro que ia pelas } \\
\text { comunidades fazendo trabalho de saúde, coleta de material laboratorial, } \\
\text { atendimento odontológico, só que isso morreu. Eu sei que o município de } \\
\text { Tonantins tem uma unidade fluvial e está parada lá no porto, porque não } \\
\text { tem médico, enfermeiro para funcionar. É aquilo que eu falei, que adianta } \\
\text { você montar a política se você não cria aquela outra parte que é a estrutura? }\end{array}$ \\
\hline
\end{tabular}

Fonte: os autores

Segundo o último levantamento do Programa Nacional de Melhoria do Acesso e da Qualidade da Atenção Básica (PMAQ, 2012), foram identificadas duas estratégias de gestões municipais de saúde amazonenses para garantir cuidado às suas populações rurais, como previsto na PNAB. A primeira foi a designação de uma unidade básica de saúde localizada na sede como referência de atendimento à população rural; a segunda estratégia foi ofertar serviços itinerantes de atenção à saúde por meio de visitas às comunidades (GARNELO et al., 2013).

Há ainda duas outras estratégias que identificamos no Estado para garantir cuidados aos povos e comunidades rurais: as ambulanchas e as unidades básicas de saúde fluviais (UBSF). As ambulanchas são um tipo de embarcação adaptada para a remoção de emergência de pacientes, as quais foram adquiridas por meio de convênio 
entre os municípios e a Fundação Amazônia Sustentável, uma das organizações não estatais que atuam no apoio à cogestão da Reserva Mamirauá. As ambulanchas facilitaram o atendimento do agente de saúde no trabalho da remoção do paciente, o qual também é responsável pela guarda do equipamento. Nas comunidades onde os ACS não residem, ela fica sob a responsabilidade da liderança comunitária que nem sempre dispõe de combustível, pois o convênio assegurava que o município iria custear a operação do equipamento (combustível e manutenção), o que, na prática, não funciona. Muito vezes, o paciente tem que custear o valor do combustível para ser atendido. As unidades básicas de saúde fluviais (UBSF) foram lançadas pela Portaria do Ministério da Saúde no 2.490, de 21 de outubro de 2011, e têm como objetivo ampliar o acesso da população ribeirinha da Amazônia Legal à atenção básica de saúde. As UBSFs funcionam 20 dias por mês em área delimitada para atuação e cada unidade é composta, minimamente, por um médico, um enfermeiro, um técnico de saúde bucal e um bioquímico ou técnico de laboratório. Estima-se em $80 \%$ a resolutividade de sua capacidade operacional, haja vista serem equipadas com recurso de transmissão via satélite, o que pode assegurar, por meio de ações de telessaúde, o apoio ao atendimento à distância.

Essas iniciativas são importantes, visto que a mobilidade dos ribeirinhos e a assistência à saúde também sofrem interferência da dinâmica hidrológica, principalmente no período de seca, quando o acesso à comunidade fica mais distante da calha do rio que permaneceu perene.

\section{Parcerias interinstitucionais $\mathrm{e}$ intersetoriais para 0 atendimento às necessidades de saúde na Reserva Mamirauá}

A elaboração dessa categoria buscou identificar a existência de intersetorialidade entre a política ambiental e a política municipal de saúde no contexto da RDSM. Os entrevistados, assim, foram indagados sobre a elaboração de projetos em parceria entre a gestão da UC e a gestão municipal.

No quadro 4 estão descritos os discursos que apontaram três ideias centrais: (1) A parceria melhorou a saúde; (2) Há dificuldade para operacionalizar as coisas; e (3) Agente não está tratando esse problema da maneira correta.

A primeira ideia central faz referência às iniciativas promovidas pelas organizações sociais envolvidas no apoio à cogestão das UCs para melhoria da infraestrutura, essas que impactaram positivamente redução de doenças de veiculação hídrica e na decisão de algumas famílias de não migrarem para a cidade, haja vista ser intenso o êxodo rural.

As duas últimas ideias centrais demonstram a dificuldade de diálogo e de parcerias entre os dois setores, isso acontecendo em decorrência de "questões políticas" e da falta de entendimento sobre a responsabilidade sanitária dos gestores. 
ATENÇÃO À SAÚDE NAS UNIDADES DE CONSERVAÇÃO AMBIENTAL NO AMAZONAS: CONFLITOS DE COMPETÊNCIA OU QUESTÃO DE RESPONSABILIDADE?

\section{Quadro 4 - As parcerias interinstitucionais e intersetoriais para o atendimento às necessidades de saúde. RDSM, 2016.}

\begin{tabular}{|c|c|}
\hline IC (síntese) & DSC \\
\hline $\begin{array}{c}\text { (1) A parceria } \\
\text { melhorou a saúde }\end{array}$ & $\begin{array}{c}\text { Pelo que eu sei, no início, o IDSM trabalhou muito na área de Uarini da } \\
\text { Reserva. Eles trabalhavam em todos os setores de Uarini essas questões de } \\
\text { saúde. Por exemplo, a questão de fossa, da água potável, era um trabalho } \\
\text { muito bonito, melhorou a saúde. Depois, com as mudanças que houve, eu não } \\
\text { sei. Mas, nessa parte de cima aqui área subsidiária, tem muito pouca } \\
\text { influência. Somente agora que tem tido mais coisas. }\end{array}$ \\
$\begin{array}{c}\text { (2) Há dificuldade } \\
\text { para }\end{array}$ & $\begin{array}{c}\text { Há problemas na relação política, o município é muito forte, e agora parece } \\
\text { que mudou, perdeu recurso. Não tem no papel com a Amurmam. Tem no } \\
\text { as coisas. } \\
\text { papel com a FAS que é a entidade de apoio a gestão. A parceria somente } \\
\text { acontece depois de muita briga. A gente também escuta muito é reclamação } \\
\text { do gestor da UC de que os prefeitos prometem, mas não cumprem. }\end{array}$ \\
$\begin{array}{c}\text { (3) A gente não } \\
\text { está tratando } \\
\text { esse problema da } \\
\text { maneira correta }\end{array}$ & $\begin{array}{c}\text { Eu não tenho muita experiência com isso não, o que eu tenho são alguns } \\
\text { relatos observacionais visto já fora do governo. O programa de aquisição de } \\
\text { alimentos para merenda escolar tem movimentado numa escala municipal, } \\
\text { algumas cadeias de produção das UCs. Mas eu acho que a gente não está } \\
\text { tratando esse problema da saúde da maneira correta. }\end{array}$ \\
\hline
\end{tabular}

Fonte: os autores

Durante as décadas de 1980-1990, a principal referência das populações rurais da RDSM no atendimento a seus problemas de saúde e educação foram as ações missionárias filantrópicas da Prelazia de Tefé com a implantação do Movimento de Educação de Base (MEB) e da Pastoral da Saúde, cujas origens remontam ao consórcio da Congregação do Espírito Santo em Tefé (atual Prelazia de Tefé) com o Serviço de Saneamento e Profilaxia Rural do Departamento Nacional de Saúde em 1921 (MOURA, 2007; HOCHMAN, 1998).

As melhorias sanitárias existentes em algumas comunidades da área de Uarini da RDSM foram iniciativas não do Estado, mas do IDSM e da Prelazia de Tefé. Entre essas, foram citadas: (i) bombas manuais para captação de água subterrânea, instaladas no início década de 1980, posteriormente abandonadas por motivos técnicos (baixa potabilidade) e financeiros (alto custo); (ii) sistemas simplificados de bombeamento; e (iii) captação e distribuição de água por energia solar fotovoltaica e por chuva, iniciada no ano 2000, que cobriu 200 domicílios em 2014 (iniciativa do IDSM), cujos recursos foram do Programa de Tecnologias Apropriadas à Várzea, em parceria com outras instituições (MOURA et al., 2016; MOURA, 2007;).

Contudo, essas iniciativas foram projetos-piloto que sofrem descontinuidade e quase sempre não recebem apoio do nível municipal, como foi o caso do $11^{\circ}$ Encontro de Parteiras Tradicionais do Médio Solimões em 2015, em que a adesão dos municípios foi insignificante e a participação da Secretaria de Estado de Saúde do Amazonas (Susam) foi custeada pelo IDSM. Além disso, a grande cheia de 2015, paralisou a rede simplificada. Mas há também paralizações por problemas técnicos e operacionais relacionados à responsabilidade pela manutenção do equipamento. 
Cabe ainda salientar que a determinação social da saúde das populações não se limita apenas às políticas de saúde e ambiental. Para a efetividade da proteção social, essas se somam a outras políticas de cunho social, econômico e político, que deveriam ser planejadas de forma integrada.

Entendemos que a Política Nacional de Saúde Integral das Populações do Campo, da Floresta e Águas (PNSIPCFA) (Portaria n 2.866/GM/MS, de 2 de dezembro de 2011) tem um forte componente de transversalidade e intersetorialidade que, desde a sua origem, foi orientada para a garantia do direito à saúde. A sua formulação resultou das agendas dos movimentos sociais no âmbito do Conselho Nacional de Saúde, sendo ela organizada pelo Grupo Terra (colegiado criado a partir da Portaria № 2.460, de 12 de dezembro de 2005 no âmbito da Secretaria de Gestão Estratégica e Participativa do Ministério da Saúde) em parceria com os conselhos de secretários de saúde (CONASEMS e CONASS) que promoveram o Grito da Terra em 2007.

No Estado do Amazonas, até o presente, a única iniciativa de discussão sobre a política foi promovida por meio do projeto "Escuta Itinerante: acesso das populações do campo e da floresta ao SUS", no município de Borba, em fevereiro de 2013. Segundo a avaliação do Departamento de Ouvidoria Geral do SUS e da Confederação Nacional dos Trabalhadores e Trabalhadoras na Agricultura - CONTAG, responsáveis pela pesquisa financiada pela Organização Pan-Americana de Saúde - OPAS, não houve nenhuma mobilização do setor de saúde e dos trabalhadores no intuito de construção de uma agenda de trabalho para discussão da mesma (BRASIL, 2013).

\section{CONSIDERAÇÕES FINAIS}

As representações discursivas do pensamento coletivo dos socioambientalistas entrevistados na pesquisa expressam preocupações em relação ao atendimento às necessidades de saúde. Elas também expressam o conhecimento existente sobre as competências municipais com a saúde, assim como a ausência de diálogo entre as políticas de saúde e a política ambiental.

O atendimento às demandas sociais está organizado de forma conflituosa, e isso acontece devido à falta de articulação entre as várias instituições que atuam nesse território.

A descentralização das competências e das responsabilidades sobre os recursos naturais por meio da cogestão das UCs impôs novos papéis e autoridades sobre os territórios, que ignoram as instituições municipais preexistentes.

A pesquisa continua capacitando os municípios sobre Política Nacional de Saúde Integral das Populações do Campo, da Floresta e Águas, cuja o processo está sendo concebido por meio de um projeto político amplo que possibilitará a estruturação de um sistema de garantias de direitos, cujo objetivo seria viabilizar o desenvolvimento de ações integradas, no intuito de promover maior acesso dos ribeirinhos aos bens e serviços sociais preconizados pela Constituição Federal de 1988. 
ATENÇÃO À SAÚDE NAS UNIDADES DE CONSERVAÇÃO AMBIENTAL NO AMAZONAS: CONFLITOS DE COMPETÊNCIA OU QUESTÃO DE RESPONSABILIDADE?

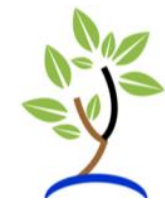

\section{AGRADECIMENTOS}

A Fundação de Amparo à Pesquisa do Estado do Amazonas pela concessão de Bolsa de Doutoramento e ao Edital Novos Talentos do Programa Inova da Fundação Oswaldo Cruz pela concessão de recursos financeiros que viabilizou a continuidade da pesquisa e a transcrição das entrevistas gravadas por bolsita contratada.

\section{REFERÊNCIAS}

AMAZONAS, T.C.E. Relatório Conclusivo de Auditoria Operacional e Ambiental em Unidades de Conservação Estaduais do Amazonas. Manaus, Tribunal de Contas do Estado do Amazonas, 2015. Disponível em: <https://www.tce.am.gov.br/portal/wpcontent/uploads/relatorio_de_auditoria_operacional_e_ambiental_em_ucs.pdf $>$. Acesso em: 15 out. 2015.

BENTES, G.D.M. Reserva de Desenvolvimento Sustentável: da realidade à legislação no Estado do Amazonas. Manaus: Editora da Universidade do Estado do Amazonas, 2006.

BRASIL. Ministério da Saúde. Relatório da "Escuta Itinerante: acesso dos povos do Campo e da Floresta ao SUS" - parceria DOGES/CONTAG. Brasília: Ministério da Saúde, 2013. Disponível em: <http://www.contag.org.br/arquivos/portal/Relatoriofinal-CONTAG.pdf>. Acesso em: 12 abr. 2015.

BRASIL. Ministério do Meio Ambiente. SNUC: Sistema Nacional de Unidades de Conservação da Natureza: Lei no 9.985, de 18 de julho de 2000; Decreto no 4.340, de 22 de agosto de 2002; Decreto $n^{\circ}$ 5.746, de 5 de abril de 2006. Plano Estratégico Nacional de Áreas Protegidas. Decreto $n^{\circ}$ 5.758, de 13 de abril de 2006. Brasília: MMA/SBF, 2011.

CALEGARE, M.G.A.; HIGUCHI, M.I.G.; FREITAS, C.C.; SIQUEIRA, M.S. Acesso a bens e serviços sociais como inclusão/exclusão social em UC no Amazonas. Novos Cadernos NAEA, Belém, v. 16, n. 1, p. 249-281, 2013.

CARMO, M.E.; GUIZARDI, F.L. Desafios da intersetorialidade nas políticas públicas de saúde e assistência social: uma revisão do estado da arte. Physis: Revista de Saúde Coletiva, Rio de Janeiro, v. 27, n. 4, p. 1265-1286, 2017.

D'ANTONA, A.O.; BUENO, M.C.D.; DAGNINO, R.S. Estimativa da população em unidades de conservação na Amazônia Legal brasileira: uma aplicação de grades regulares a partir da Contagem 2007. Revista Brasileira de Estudos de População, Belo Horizonte, v. 30, n. 2, p. 401-428, 2013. 
ATENÇÃO À SAÚDE NAS UNIDADES DE CONSERVAÇÃO AMBIENTAL NO AMAZONAS: CONFLITOS DE COMPETÊNCIA OU QUESTÃO DE RESPONSABILIDADE?

FERREIRA, L.C. Conflitos sociais e o uso de recursos naturais: breves comentários sobre modelos teóricos e linhas de pesquisa. Política \& Sociedade, Florianópolis, v. 4, n. 7, p. 105-118, 2005.

FRANCO, J.L.A. O conceito de biodiversidade e a história da biologia da conservação: da preservação da wilderness à conservação da biodiversidade. História, São Paulo, v. 32, n. 2, p. 21-48, 2013.

GARNELO, L.; VIEIRA, J.R.; SOUZA, M.L.P. Avaliação externa do PMAQ no Amazonas: experiência e narrativas sobre a implementação da Política Nacional de Atenção Básica. In: FAUSTO, M.C.R.; FONSECA, H.M.S. Rotas da Atenção Básica no Brasil: experiências do trabalho de campo PMAQ-AB. Rio de Janeiro: Saberes, 2013. p. 60-87.

GODOY, L.R.C.; LEUZINGE, M. D. Características e tendências. 2015. Disponível em: $<$ https://www2.senado.leg.br/bdsf/bitstream/handle/id/512457/001041600.pdf?seque nce=1>. Acesso em: 30 set. 2017.

GOTTEMS, L.B.D.; PIRES, M.R.G.M.; CALMON, P.C.D.P.; ALVES, E.D. O modelo dos múltiplos fluxos de Kingdon na análise de políticas de saúde: aplicabilidades, contribuições e limites. Saúde e Sociedade, São Paulo, v. 22, n. 2, p. 511-520, 2013.

GUERRA, A.J.T.; COELHO, M.C.N. Unidades de conservação: abordagens e características geográficas. Rio de Janeiro: Bertrand Brasil, 2009. 296p.

GUIVANT, J.S. Apresentação do Dossiê Mapeando os caminhos da Sociologia Ambiental. Política \& Sociedade, Florianópolis, v. 4, n. 7, p. 9-25, 2005.

HAESBAERT, R. Da desterritorialização à multiterritorialidade. In: Anais do X Encontro de Geógrafos da América Latina, 2005, São Paulo: USP, p. 6774-6792.

HOCHMAN, G.A era do saneamento. Sao Paulo: Hucitec, 1998.

KINGDON, J.W. Agendas, alternatives and public policies. New York: Longman, 2003.

LEFÈVRE, F.; LEFÈVRE, A.M.C. Discurso do sujeito coletivo: um novo enfoque em pesquisa qualitativa. Caxias do Sul (RS): Educs, 2005.

MACHADO, P.A.L. Direito Ambiental no Brasileiro. São Paulo: Malheiros Editores, 2016.

MARTINS, A. Conflitos ambientais em unidades de conservação: dilemas da gestão territorial no Brasil. Revista Bibliográfica de Geografía y Ciencias Sociales, Barcelona, v. XVII, n. 989, p. 15, 2012. 
ATENÇÃO À SAÚDE NAS UNIDADES DE CONSERVAÇÃO AMBIENTAL NO AMAZONAS: CONFLITOS DE COMPETÊNCIA OU QUESTÃO DE RESPONSABILIDADE?

MATTA, G.C.; MOROSINI, M.V.G. Atenção à saúde. In: PEREIRA, I.B.; LIMA, J.C.F. (Ed.). Dicionário de Educação Profissional em Saúde. 2. ed. Rio de Janeiro: EPSJV, 2009. p. 39-44.

MEDEIROS, R.; IRVING, M.A. Áreas protegidas e inclusão social: construindo novos significados. Rio de Janeiro: Fundação Bio-Rio, 2006.

MENDES, E. V. As redes de atenção à saúde. Brasília: OPAS, 2011.

MOURA, E.A.F. Práticas socioambientais na Reserva de Desenvolvimento Sustentável Mamirauá, Estado do Amazonas, Brasil. Tese (Doutorado em Desenvolvimento Sustentável do Trópico Úmido), Universidade Federal do Pará, Belém, 2007.

MOURA, E.A.F.; NASCIMENTO, A.C.S; CORRÊA, D.S.D.S.; ALENCAR, E.F.; SOUSA, I.S; Sociodemografia da Reserva de Desenvolvimento Sustentável Mamirauá: 2001-2011. Tefé (AM): Instituto de Desenvolvimento Sustentável de Mamirauá, 2016.

MULLER, P.; SUREL, Y. A Análise das Políticas Públicas. Pelotas: Educat, 2004.

NICOLAU, K.W.; ESCALDA, P.M.F.; FURLAN, P.G. Método do Discurso do Sujeito Coletivo e Usabilidade dos Softwares Qualiquantisoft e DSCsoft na Pesquisa Qualiquantitativa em Saúde. Fronteiras: Journal of Social, Technological and Environmental Science, v. 4, n. 3, p. 87, 2015.

PAIM, J.S. Descentralização das ações e serviços de saúde no Brasil e a renovação da proposta "saúde para todos". In: PAIM, J.S. Saúde, Políticas e Reforma Sanitária. Salvador (BA): CEPES/ISC, 2002. p. 295-323.

SANTILLI, J. Socioambientalismo e novos direitos: proteção jurídica à diversidade biológica e cultural. São Paulo: Editora Peirópolis, Instituto Socioambiental e Instituto Internacional de Educação do Brasil, 2005.

SECCHI, Leonardo. Políticas Públicas: conceitos, esquemas de análise, casos práticos. São Paulo: Cengage Learning, 2010.

SOUZA, J.V.C. Congressos Mundiais de Parques Nacionais da UICN (1962-2003): registros e reflexões sobre o surgimento de um novo paradigma para a conservação da natureza. Dissertação (Mestrado em Desenvolvimento Sustentável), Universidade de Brasília, Brasília, 2013.

VALLEJO, L.R. Políticas Públicas e Conservação Ambiental: Territorialidades em Conflito nos Parques Estaduais da Ilha Grande, da Serra da Tririrca e do Desengano(RJ). Tese (Doutorado em Geografia), Universidade Federal Fluminense, Niterói, 2005. 
ATENÇÃO À SAÚDE NAS UNIDADES DE CONSERVAÇÃO AMBIENTAL NO AMAZONAS: CONFLITOS DE COMPETÊNCIA OU QUESTÃO DE RESPONSABILIDADE?

VERÍSsIMO, A.; ROLLA, A.; VEDOVETO, M.; FUTADA, S.M. Áreas Protegidas na Amazônia Brasileira: avanços e desafios. Belém/São Paulo: Imazon e ISA, 2011.

WALLAUER, M. T. Sistema de unidades de conservação federais no Brasil: um estudo analítico de categorias de manejo. Dissertação (Mestrado em Engenharia Ambiental), Universidade Federal de Santa Catarina, Santa Catarina, 1998. 